\title{
Drinking water biofilm assessment of total and culturable bacteria under different operating conditions
}

\author{
L. C. SIMÕES ${ }^{1}$, N. AZEVEDO ${ }^{1,2}$, A. PACHECO ${ }^{1}$, C. W. KEEVIL ${ }^{2} \&$ M. J. VIEIRA ${ }^{1}$ \\ ${ }^{1}$ Centro de Engenharia Biológica, Universidade do Minho, Braga, Portugal and ${ }^{2}$ Environmental Healthcare Unit, School of \\ Biological Sciences, University of Southampton, UK
}

(Received 11 October 2005; accepted 10 fanuary 2006)

\begin{abstract}
Monitoring of biofilms subjected to different operating conditions was performed using a flow cell system. The system was fed by chlorine-free tap water, with and without added nutrients $\left(0.5 \mathrm{mg} \mathrm{1^{-1 }}\right.$ carbon, $0.1 \mathrm{mg} \mathrm{1^{-1 }}$ nitrogen and $0.01 \mathrm{mg} 1^{-1}$ phosphorus), and biofilms were grown on polyvinyl chloride (PVC) and stainless steel (SS) coupons, both in laminar and turbulent flow. The parameters analysed were culturable cells, using R2A, and total bacteria, which was assessed using the 4,6-diamino-2-phenylindole (DAPI) staining method. The impact of the different operating conditions in the studied parameters was established using Multivariate Analysis of Variance (MANOVA). From the most relevant to the least relevant factor, the total and culturable bacteria in biofilms increased due to the addition of nutrients to water $(\mathrm{F}=20.005$; $p<0.001)$; the use of turbulent $(\operatorname{Re}=11000)$ instead of laminar $(\operatorname{Re}=2000)$ hydrodynamic flows $(\mathrm{F}=9.173 ; p<0.001)$; and the use of PVC instead of SS as the support material $(\mathrm{F}=2.848 ; p=0.060)$. Interactions between these conditions, namely between surface and flow $(\mathrm{F}=8.235 ; p<0.001)$ and also flow and nutrients $(\mathrm{F}=5.498 ; p<0.05)$ have also proved to significantly influence biofilm formation. This work highlights the need for a deeper understanding of how the large spectrum of conditions interact and affect biofilm formation potential and accumulation with the final purpose of predicting the total and culturable bacteria attached to real drinking water distribution pipes based on the system characteristics.
\end{abstract}

Keywords: Biofilm, drinking water, nutrient content, flow rate, support material

\section{Introduction}

Bacteriologically safe drinking water is one of the main goals that both drinking water companies and governments worldwide try to achieve. However, the incidence of water-borne infections caused by bacterial, viral, and parasitic microorganisms is still a major economic and, in some cases social burden, all around the globe. According to the World Health Organisation, diseases associated with unsafe water, sanitation and hygiene cause approximately 1.7 million deaths each year (Prentice, 2002). Pathogen survival in treated water has been associated with biofilms growing at the water-pipe material interface, where the protective layer of polysaccharides can maintain microorganisms in a viable state, mainly due to a lower efficiency of chlorine action that is quenched in this type of naturally occurring structure (Keevil, 2002).

The amount of biofilm in a given system after a certain period of time depends on biofilm accumulation, which has been defined as the balance between bacterial attachment from the planktonic phase, bacterial growth within the biofilm and biofilm detachment from the surface (Stoodley et al. 1999). When that balance is null, the biofilm is said to have reached a steady-state. The final amount of biofilm in that state, which can be assessed by cell counts or biofilm mass, is directly related to the biofilm formation potential of that system (van der Kooij, 1999).

Different systems have been developed to study biofilms and the influence of the large spectrum of conditions that are known to alter their biofilm formation potential. Relevant factors include water temperature and $\mathrm{pH}$, support material, concentration of disinfectant, flow rates, microbiological quality and organic substrata in the water (Camper et al. 1999). However, most studies assess only one variable at a time (e.g. Pedersen, 1990; Rogers et al. 1994a; Kerr et al. 1999; Zacheus et al. 2000; Dunsmore et al. 2002; Niquette et al. 2000; Soini et al. 2002), and apart from notable exceptions (Block et al. 1993; Stoodley et al.1999), scarce

Correspondence: Maria J. Vieira, Centro de Engenharia Biológica, Universidade do Minho, $4700-057$ Braga, Portugal. Fax: +351 25367 8986. E-mail: mjv@deb.uminho.pt 
attempts have been made so far to study interrelationships and compare the relative importance of these different factors. In addition, the complexity of the microenvironment under study and even the use of different methodologies and biofilm growth systems lead in some cases to ambiguous or not easily comparable results.

In this study, a flow cell system already described (Pereira et al. 2002a), was used to observe the effect that different flow conditions, the nutrient contents of the water and the support materials might have on water-exposed biofilms. Based on the results obtained, a quantitative approach was used to establish a "hierarchy" of importance for the influence of these factors on biofilm accumulation. Additionally, relevant interactions between the factors were determined.

\section{Methods}

Flow cell system

The configuration of the system is presented in Figure 1. Briefly, tap water is collected in a reservoir, which is connected to one of two consecutive granular activated carbons (GAC) filter columns. It has been shown elsewhere that the first GAC filter eliminates free chlorine and biodegradable matter contained in the tap water, while the second is a biologically activated filter providing a continuous bacterial inoculum to the reactor (Morin \& Camper, 1997). To avoid the presence of large carbon particles released from the columns, two filters (pore sizes $20 \mu \mathrm{m}$ and $5 \mu \mathrm{m}$ ) were placed between the second GAC filter and the mixing tank. This tank supplies a constant inoculum at a flow rate of approximately $0.021 \mathrm{~h}^{-1}$ into each of the flow cells. The absence of free chlorine in the mixing tank was certified by regular sampling, using the free chlorine ion specific meter HI-93701 (Hanna Instruments, USA).

Two flow cells were used in parallel, according to the procedure described by Pereira et al. (2002a). Each consisted of a semicircular perspex duct $43 \mathrm{~cm}$ in length and with a $1 \mathrm{~cm}$ equivalent diameter (the internal diameter of the half cylinder was $1.6 \mathrm{~cm}$ ), where the biofilm coupons were inserted. These rectangular coupons $(2.4 \times 1.4 \mathrm{~cm})$, consisting of either stainless steel ASI 316 2R (SS) or polyvinyl chloride (PVC) were glued to pieces of perspex that

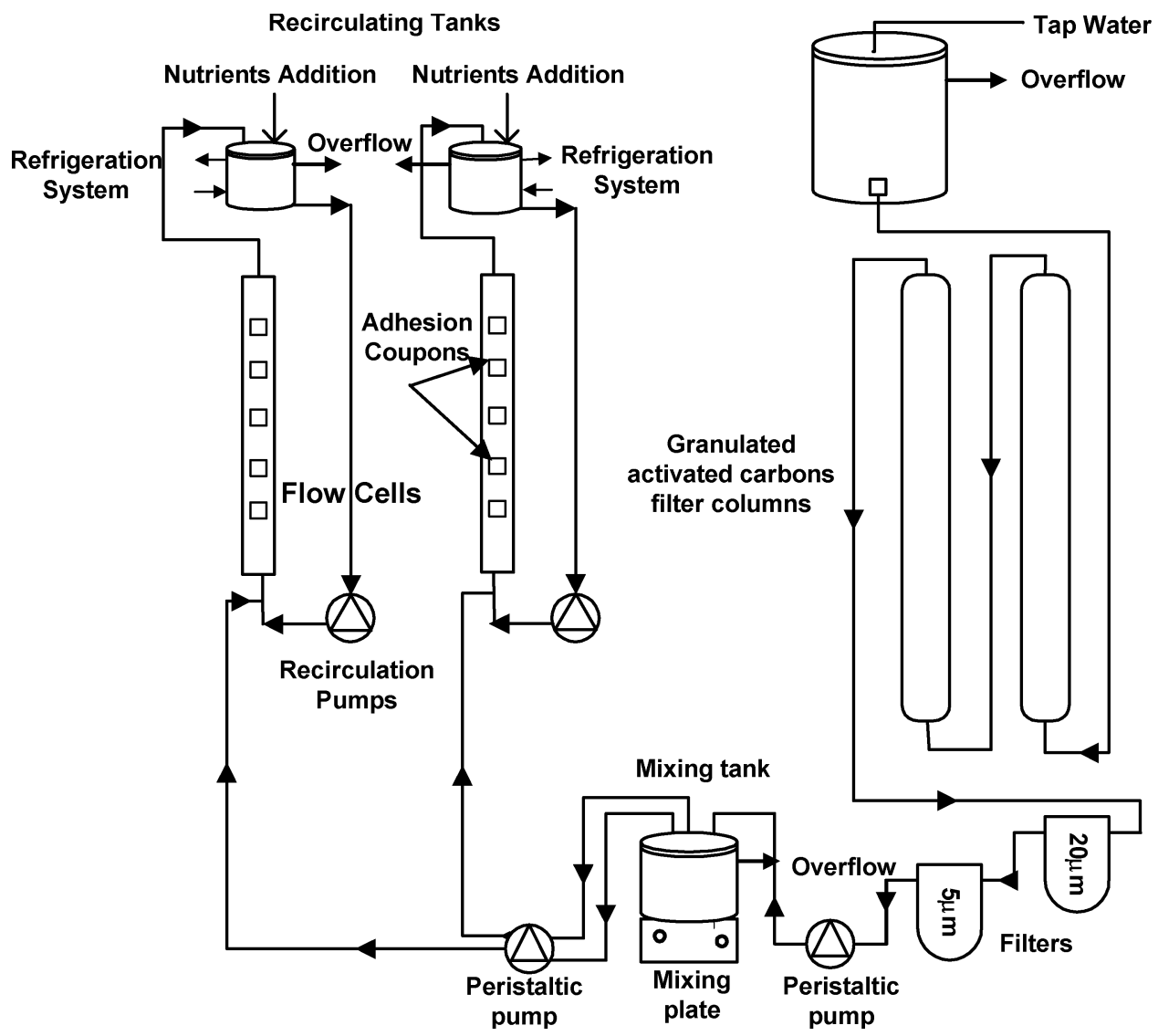

Figure 1. Experimental set-up, showing the GAC filter columns and the two parallel flow cells containing the SS and PVC removable coupons. 
could be fitted in the apertures. Biofilms were formed on those coupons whose upper faces were in contact with the tap water circulating in the flow cell reactor system. It was possible to remove separately each of the rectangular coupons without disturbing the biofilm formed on the others and without stopping the flow. This was managed because outlet ports were disposed on the round face of the flow cell between each two adjacent removable pieces of perspex that allowed the deviation of the circulating flow from the point where the reactor was opened. The temperature in the recirculation tanks was maintained at $20 \pm 1^{\circ} \mathrm{C}$ by an external refrigeration mechanism (Thermomix ${ }^{\mathbb{R}} \mathrm{BU}$, B. Braun-Biotech SA). The addition of nutrients, whenever applicable, was made at these tanks.

\section{Flow rate and nutrients addition}

Using this system, 4 separate conditions were tested, viz. turbulent flow, with and without addition of nutrients (carbon, nitrogen and phosphorus), and laminar flow, also with and without addition of nutrients. The water flow rate through the flow cells was controlled by recirculating the water by means of recirculation pumps. The turbulent flow rate was $4001 \mathrm{~h}^{-1}(\operatorname{Re}=11000)$, whereas the laminar flow rate was $731 \mathrm{~h}^{-1}(\operatorname{Re}=2000)$. Carbon, nitrogen and phosphorus were continuously added in two of the experiments, so that the added final concentration in the system was $0.5,0.1$ and $0.01 \mathrm{mg} \mathrm{l}^{-1}$, respectively (Table I). For each condition, PVC and SS coupons were tested in parallel, one material in each flow cell.

\section{Biofilm monitoring and planktonic cell sampling}

All the following procedures were undertaken under aseptic conditions. The experiment was carried on for at least $2 \mathrm{~d}$ after the biofilm reached a steady-state (considered to occur when constant values were obtained both for CFU and TB), after which the

Table I. Compounds continuously added to the water in the recirculation tanks to obtain the desired concentrations of carbon, nitrogen and phosphorus in the system.

\begin{tabular}{lcc}
\hline Compounds & $\begin{array}{c}\text { Stock concentration } \\
\left(\mathrm{g} \mathrm{l}^{-1}\right)\end{array}$ & $\begin{array}{c}\text { Final concentration } \\
\left(\mu \mathrm{g} \mathrm{I}^{-1}\right)\end{array}$ \\
\hline $\begin{array}{l}\text { Sodium acetate } \\
\text { trihydrate }\end{array}$ & 176.20 & 859.83 \\
$\begin{array}{l}\text { Ethanol } \\
\text { Propionaldehyde }\end{array}$ & 35.80 & 174.70 \\
$\quad 98 \%$ & 30.10 & 146.88 \\
$\begin{array}{l}\text { Propionic acid } \\
\text { Potassium nitrate }\end{array}$ & 72.90 & 355.74 \\
Sodium phosphate & 108.30 & 720.67 \\
$\quad$ dibasic dihydrate & 8.53 & 56.76 \\
\hline
\end{tabular}

experiment was terminated and the flow cells sterilised. The sampling was made from the top to the bottom under aseptic conditions and the rectangular coupons removed were substituted with new coupons that were previously cleaned, immersed in ethanol $(70 \% \mathrm{v} / \mathrm{v})$ and rinsed in sterile distilled water. The coupons removed were gently washed with sterile sodium phosphate buffer $(\mathrm{pH}=7.0)$ to remove loosely attached microorganisms and scraped with a scalpel into tubes containing $10 \mathrm{ml}$ of sterile phosphate buffer. Before serial dilution, tubes were vortexed for $2 \mathrm{~min}$ and used to assess both colony forming units (CFU) and total cell counts (TB). Monitoring of planktonic bacteria was also performed on the mixing and recirculation tanks whenever biofilm sampling was carried out. Simultaneously, a water sample was taken from the tanks for temperature and $\mathrm{pH}$ measurement.

\section{Total and culturable cell counting of biofilms and water}

TB were obtained by filtering a volume (up to $10 \mathrm{ml}$ as a function of the bacterial concentration) through a $25 \mathrm{~mm}$ black Nuclepore ${ }^{\circledR}$ polycarbonate membrane with a pore size of $0.2 \mu \mathrm{m}$ (Whatman, UK). Before the filtration step, $2 \%(\mathrm{v} / \mathrm{v})$ formaldehyde (Merck, Germany) was added to the solution for fixation and preservation of the sample. After filtration, cells in the membrane were stained with $100 \mu \mathrm{g} \mathrm{ml} \mathrm{ml}^{-1}$ 4,6-diamino-2-phenylindole (DAPI) (Sigma, USA) for $5 \mathrm{~min}$ and preparations were stored at $4^{\circ} \mathrm{C}$ for up to $7 \mathrm{~d}$ in the dark before visualisation. No significant decay of fluorescence was noticed during this time span. Cells were visualised under an epifluorescence microscope (Carl Zeiss, Germany) equipped with a filter sensitive to DAPI fluorescence $(359 \mathrm{~nm}$ excitation filter in combination with a $461 \mathrm{~nm}$ emission filter). A total of 20 fields were counted and the average of three membranes was used to calculate total cells per $\mathrm{cm}^{2}$ or $\mathrm{ml}$ of sample.

CFUs were evaluated by standard culture methods on R2A (Oxoid, UK) prepared according to the manufacturers instructions. Triplicate plates were used for each dilution, for both biofilms and water. CFUs were counted after $15 \mathrm{~d}$ incubation at room temperature (approximately $23^{\circ} \mathrm{C}$ ), and the results

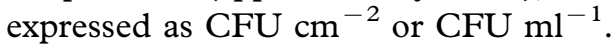

\section{Statistical analysis}

A Multivariate Analysis of Variance (MANOVA) was used to quantitatively assess the correlation and interactions between time, support material, nutrient addition and flow rates to biofilm formation. Tests of between-subjects effects were then performed to discriminate between effects on TB and CFU. Exact 
F statistics were performed and $p$ value estimated using the Pillai's trace test criteria and results were considered to be significant if $p<0.05$. All computations were performed using the SPSS software package (SPSS Inc., USA) (Pallant, 2001).

\section{Results}

\section{Biofilm monitoring}

Biofilm accumulation in all experiments, expressed both in CFU and TB, increased markedly in the first few days, following a sigmoidal curve (Figure 2). Generally, TB increased at a greater rate than CFU therefore, the ratio of culturable bacteria/total bacteria had a tendency to increase as steady state was reached. Steady state surface concentrations for TB ranged from $10^{5}$ to $10^{7} \mathrm{~TB} \mathrm{~cm}^{-2}$ and for culturable bacteria from $10^{4}$ to $10^{6} \mathrm{CFU} \mathrm{cm}^{-2}$, depending on the conditions used. The time biofilms take to reach the steady state depends on many factors, e.g. the elimination of chlorine and the supply of a biological inoculum by the granulated activated columns included in the system were major determinants in allowing the steady state to be reached relatively quickly, within $6-10 \mathrm{~d}$, as opposed to about $100 \mathrm{~d}$ (Holden et al. 1995), 4 months (Pedersen, 1990), and 11-16 d (Kerr et al. 1999) in other studies.

The morphology of the biofilms was markedly different depending on the flow regime. Coverage of the surface was higher and more homogeneous for biofilms grown in turbulent flow, whereas biofilms grown in laminar flow were more patchy. Direct visualisation of a mature DAPI-stained biofilm grown in laminar flow allowed the detection of

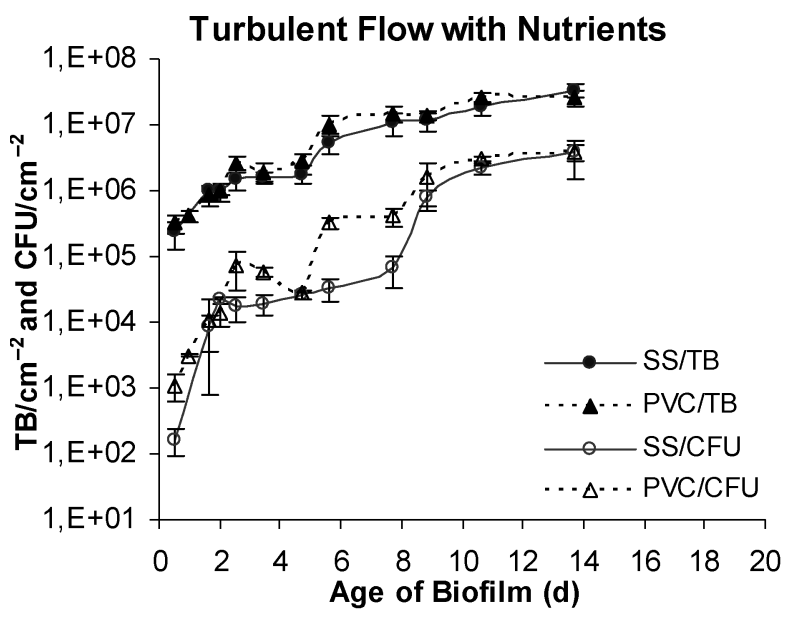

(a)

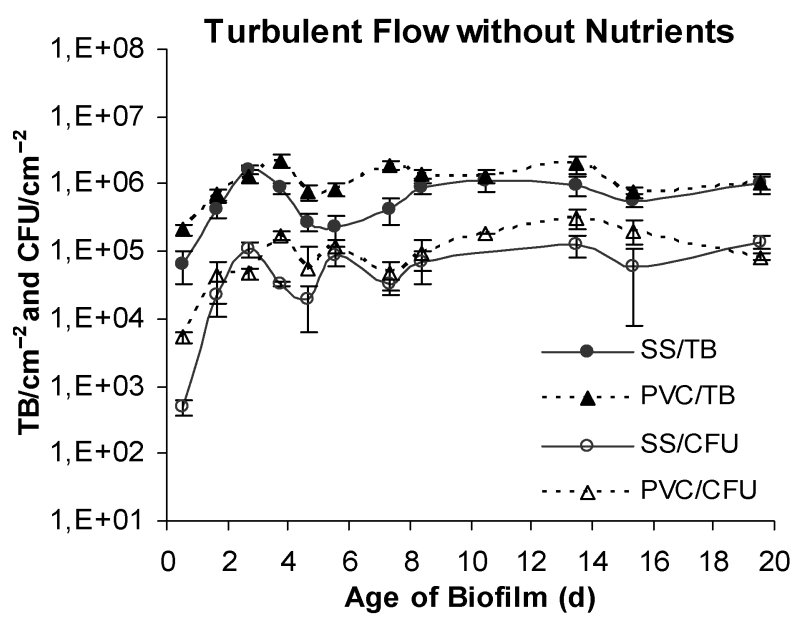

(b)

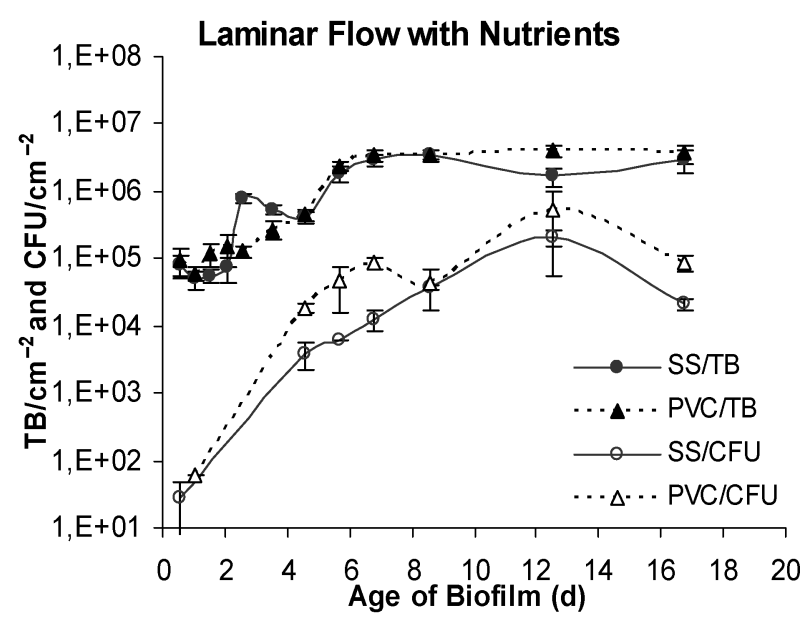

(c)

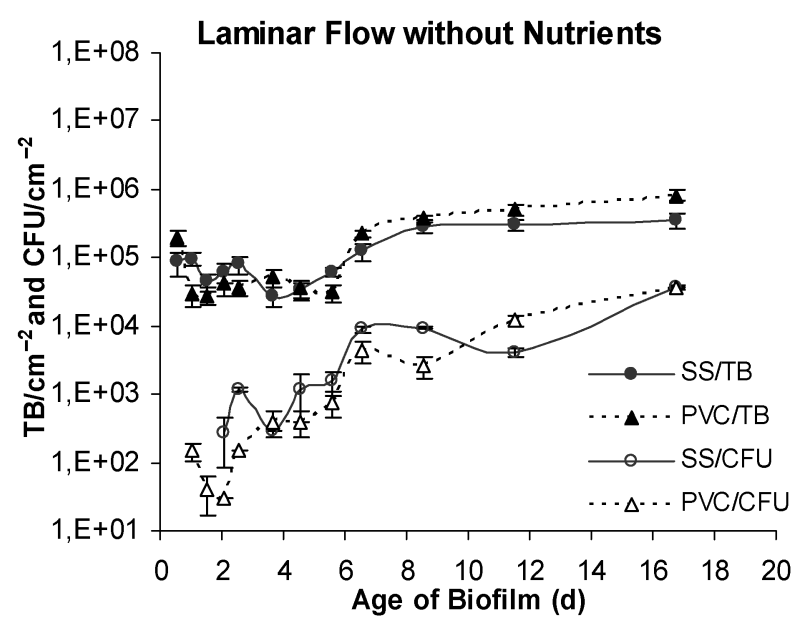

(d)

Figure 2. Kinetics of biofilm growth obtained for the different conditions. Biofilm accumulation (assessed by TB and CFU) on SS and PVC surfaces. $a=$ turbulent flow with nutrients; $b=$ turbulent flow without nutrients; $c=$ laminar flow with nutrients; $d=$ laminar flow without nutrients. 
bacteria in different levels of focus, revealing the presence of typical biofilm structures such as stacks or fronds (Figure 3). It was also found that DAPIstained bacteria fluoresced less brightly in the experiments without nutrients as opposed to those with nutrients. Saby et al. (1997) reported that chlorinated bacteria expressed a lower DAPI signal intensity, caused by the disinfectant action over the structure of bacterial DNA. The present observations suggest that different physiological states of the bacteria (induced by the absence and presence of nutrients) also affect DAPI staining (results not shown).

\section{Relevance of different conditions on biofilm accumulation}

Based on the results obtained and shown in Figure 2, a MANOVA analysis was performed to assess the influence that each of the parameters had on biofilm accumulation (Table II). Analysis of this Table has shown that all factors (except for the type of surface; $p=0.060$ ) influenced biofilm accumulation but to different extents. Besides presenting a larger multivariate $\mathrm{F}$ value, nutrients influenced both TB and CFU significantly, whereas the effect of flow was mostly observed on CFU. This implies that, in this study, nutrients were the most relevant factor, followed by the hydrodynamics conditions. The support material only significantly influenced CFU counts and had the lowest multivariate $\mathrm{F}$ value. It was therefore the least relevant factor in biofilm accumulation. It can also be observed from Table II that interactions between the pairs of factors surface/flow regime and flow regime/nutrients were statistically significant. However, the significant effects obtained in the multivariate $\mathrm{F}$ value for the pair surface/flow regime were totally derived from interactions involving the CFU counts.

Even though the importance that each factor has on biofilm accumulation has been described above, it is hard to tell which condition increases cell counts by simply observing Figure 2. For an easier visualisation of the effect that each of the conditions has on biofilm numbers, the average of the values after the steady state was reached was calculated. From considering the average of the samples taken after $6 \mathrm{~d}$ from the Figure 2 data it can be determined that steady state was established at day 6 in the laminar flow with and without nutrients and in the turbulent flow without nutrients but at day 10 for the turbulent flow with nutrients (Figure 4). It was clearly observed that added nutrients, turbulent regimes and PVC all contributed to increased levels of biofilm cell numbers.

As expected, simultaneous use of turbulent conditions and higher nutrient concentration lead to

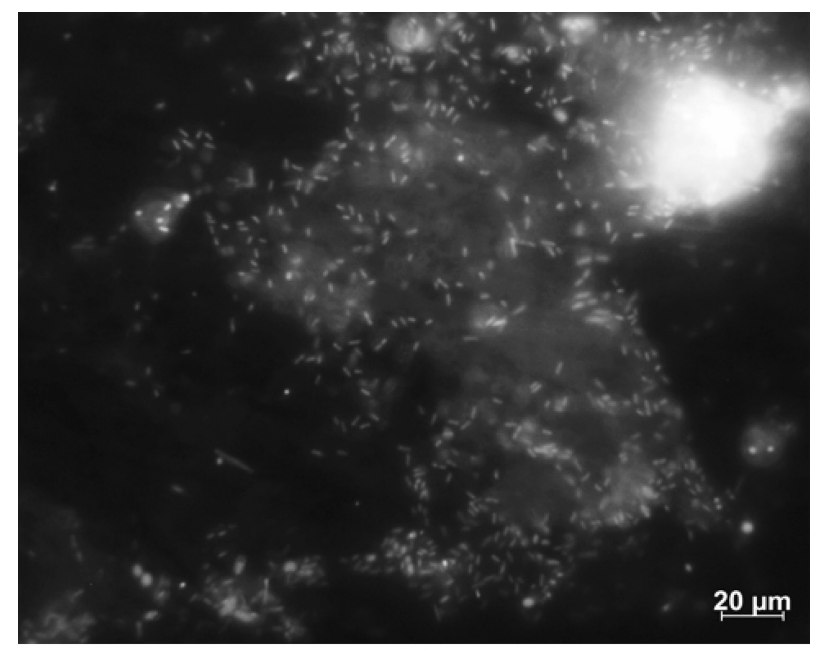

(a)

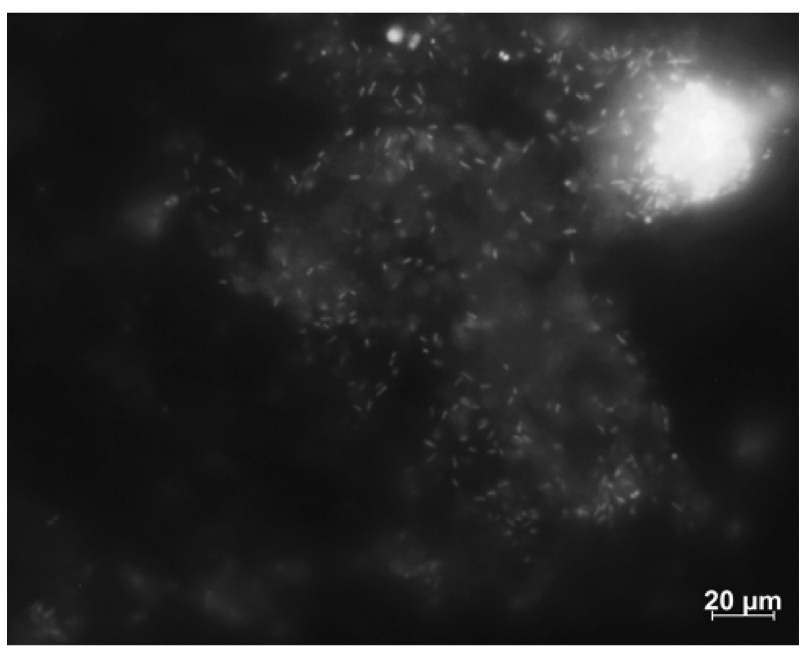

(b)

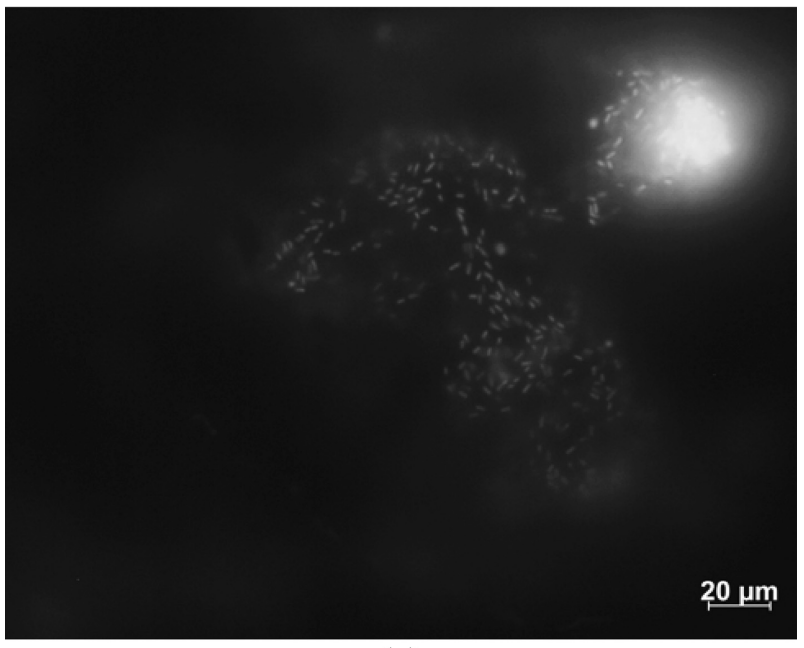

(c)

Figure 3. DAPI-stained frond of a biofilm formed on SS under laminar flow with nutrients at different focal planes. $a=$ base level; $b=$ middle level; $\mathrm{c}=$ top level. Frond height $=\sim 40 \mu \mathrm{m}$. Scale bar $=20 \mu \mathrm{m}$.

even higher numbers of TB and CFU in biofilms. In the steady state, the percentage of culturable cells was higher in turbulent flow ( $\sim 9 \%$ of the TB) than 
Table II. Results obtained with the MANOVA statistical test. F value was estimated using the Pillai's trace post hoc method. A test of between-subject effect was also performed to assess the influence of each factor on the dependent variables CFU and TB individually. Interactions between time and the other components are not shown.

\begin{tabular}{lccc}
\hline Factor & $\begin{array}{c}\text { Multivariate } \\
\text { F value }\end{array}$ & $\begin{array}{c}\text { Univariate F value } \\
\text { for effect on CFU }\end{array}$ & $\begin{array}{c}\text { Univariate F value } \\
\text { for effect on TB }\end{array}$ \\
\hline Time & $6,519^{* * *}$ & $5,916^{* * *}$ & $8,573^{* * *}$ \\
Surface & $2,848^{*}$ & $5,615^{* *}$ & $1,624^{*}$ \\
Flow regime & $9,173^{* * *}$ & $18,412^{* * *}$ & $3,676^{*}$ \\
Nutrients & $20,005^{* * *}$ & $18,112^{* * *}$ & $36,389^{* * *}$ \\
Surface $\times$ Flow regime & $8,235^{* * *}$ & $14,796^{* * *}$ & $0,133^{*}$ \\
Surface $\times$ Nutrients & $1,156^{*}$ & $2,299^{*}$ & $0,587^{*}$ \\
Flow $\times$ Nutrients & $5,498^{* *}$ & $8,659^{* *}$ & $6,847^{* *}$ \\
Surface $\times$ Flow $\times$ Nutrients & $1,999^{*}$ & $3,784^{*}$ & $0,126^{*}$ \\
\hline
\end{tabular}

$* * * p<0.001 ; * * p<0.05 ; * p>0.05$.

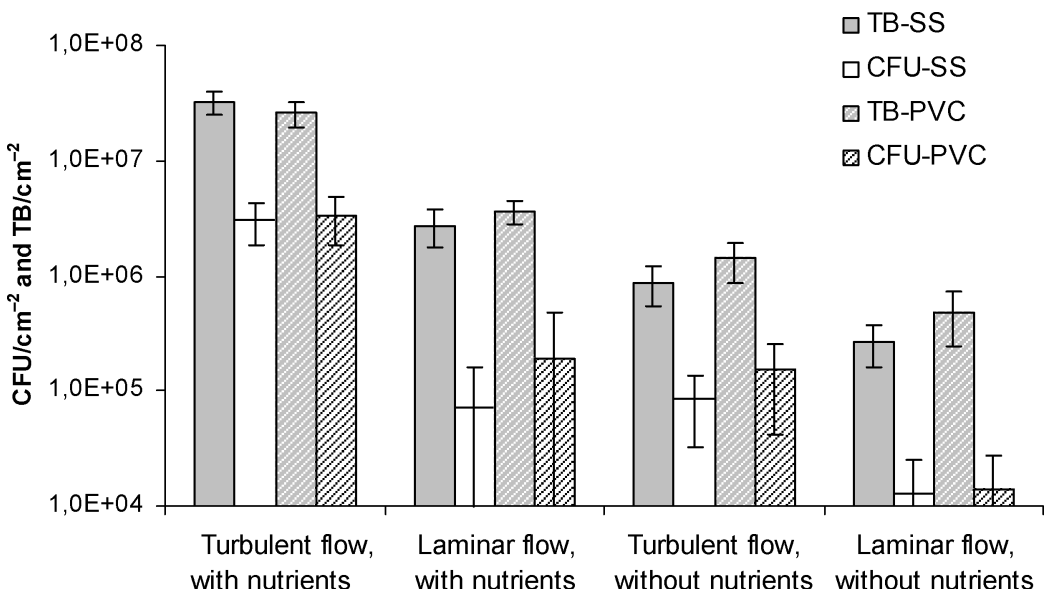

Figure 4. Averages of the CFU and TB values obtained from the points taken after the kinetics of biofilm formation reached a steady state, viz. $6 \mathrm{~d}$ for the laminar flow with and without nutrients and the turbulent flow without nutrients but $10 \mathrm{~d}$ for the turbulent flow with nutrients.

in laminar flow $(\sim 4 \%)$. Therefore, the increased nutrients and the change for a turbulent flow rate resulted in a very similar effect on CFU values, an outcome that is confirmed by the similar univariate $\mathrm{F}$ value for effect in CFU obtained by flow regime and nutrients in Table II.

\section{Comparison between bacteria on biofilms and planktonic bacteria}

In order to confirm, as suggested by other authors (Van der Wende et al. 1989; Kerr et al. 1999; Boe-Hansen et al. 2002), if a possible correlation between bacteria in biofilms and planktonic bacteria in the system (samples taken from the recirculation tanks) could be determined, results gathered during all experiments were plotted and the correlation coefficient determined (Figure 5). It was verified that TB provides a poor way to infer the biofilm accumulation status $\left(\mathrm{r}^{2}=0.27\right)$ whereas CFU provides a slightly better correlation coefficient, $\mathrm{r}^{2}=0.59$ $(p<0.05)$.

\section{Discussion}

\section{Influence of support material on biofilm formation}

In most of the experiments, comparing two different support materials, PVC supported higher growth. However, the similarity of both materials in promoting bacterial attachment and survival on the surface allows other factors, such as the microbiological quality of the inlet water or sampling variability, to influence the final result. Therefore, in some of the experiments CFU counts in SS were higher than in PVC. Another perhaps less credible explanation is that results between materials are different according to the conditions under which they are exposed. In previous studies, authors could not conclude which of these materials would support more or less biofilm growth (Pedersen, 1990; Zacheus et al. 2000), although Rogers et al. (1994a) observed three times more TB on PVC than on SS. So far, only copper seems to be an indisputably better support material in respect to microbiological growth control in biofilms (Rogers et al. 1994b). 


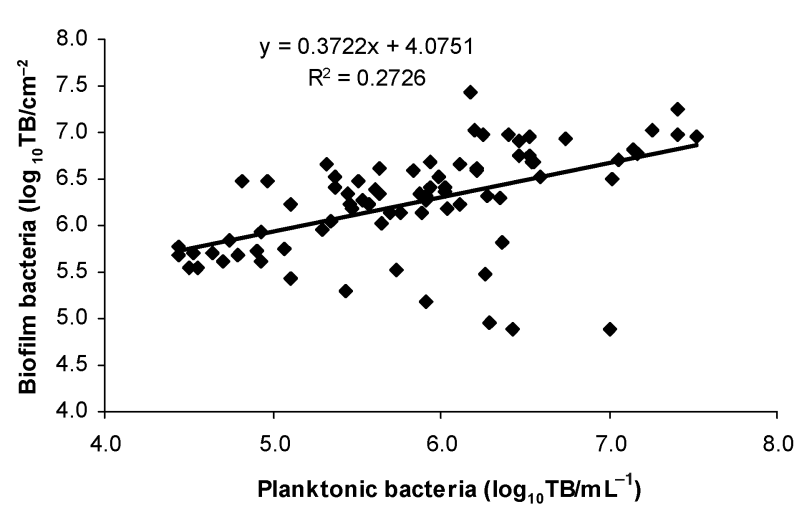

(a)

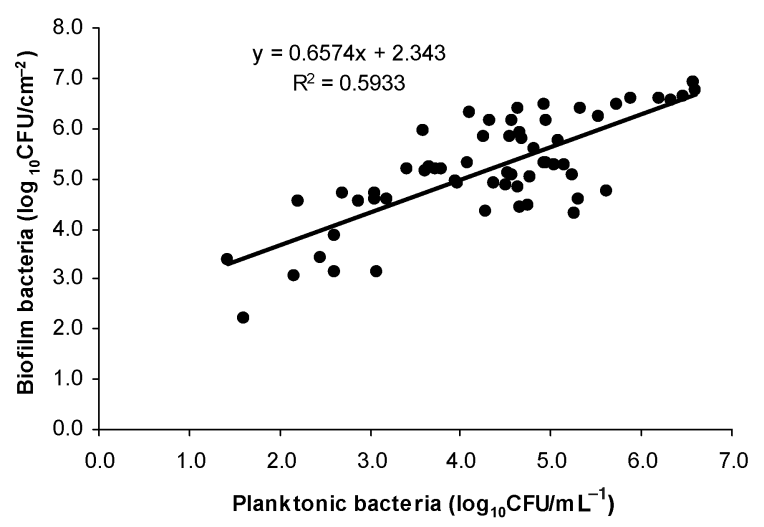

(b)

Figure 5. Relationship between TB (a) and CFU (b) in the biofilm and those in the effluent bulk water flowing from the flow cells systems.

Influence of flow conditions on biofilm formation

Several papers have been published concerning the effect of hydrodynamics on biofilms, but these are mostly concerned with changes in structure and not with viable or total counts (Stoodley et al. 1999; Vieira \& Melo 1999; Dunsmore et al. 2002; Wasche et al. 2002; Horn et al. 2003). Biofilms formed under turbulent conditions are more compact (Vieira et al. 1993; Stoodley et al. 1999; Dunsmore et al. 2002; Wasche et al. 2002; Horn et al. 2003), which might implicate a more difficult mass transfer due to the less porous structure. On the other hand the turbulence caused by the higher fluid velocity increases mass transfer to provide increased nutrient supply for a denser biofilm.

It was confirmed here that the different biofilm morphologies found in laminar and turbulent flow influence the number of culturable and total cells. In addition, the percentage of culturable cells was found to be higher for turbulent regimes, a result that is in agreement with the higher respiratory activity of bacteria reported by Pereira et al. (2002a) for this type of flow condition. Again, the reason for this behaviour lies in the biofilm structure. The presence of higher stacks in laminar flow biofilms may decrease the internal mass transfer inside these structures, rendering the inner cells less active and thus decreasing their culturability, which contrasts with the more uniform distribution and thinner layer of cells formed under turbulent flow. Because biofilms formed under laminar conditions tend to be more prone to fluctuations in mass over time due to sloughing off and regrowth (Pereira et al. 2002b), larger standard deviation values were observed when calculating the averages in Figure 4.

\section{Nutrient addition influence on biofilm formation}

In accordance with the results obtained, other authors have already observed that large concentrations of nutrients in the system increased the number of cells in biofilms (Volk \& LeChevallier, 1999; Frias et al. 2001). The importance of this parameter is furthermore underlined by the conclusions that maintaining low levels of nutrients is an effective way of controlling regrowth in drinking water distribution systems (van der Kooij, 1992). However, the use of different methods/systems for measuring nutrient content does not allow a more detailed comparison between the results obtained by the different authors.

\section{Interactions between different factors}

Strong interactions between surface and flow regime were detected but only in terms of CFU counts. Conversely, interactions among flow regime and nutrients had a much greater influence than expected. It has been shown here that simultaneous use of turbulent conditions and higher nutrient concentration leads to even higher numbers of TB and CFU. Stoodley et al. (1999) have already observed that depending on the relationship between nutrient levels and hydrodynamic conditions, the biofilm morphotype could exhibit at least three different forms. In the present study, the interactions were detected both at the CFU and TB level and might represent a manifestation of these different morphotypes.

\section{Relevance of different conditions for biofilm accumulation}

The main objective of this work was to compare the relevance of different factors involved in biofilm CFU and TB counts. Block et al. (1993) also attempted to achieve this goal using an industrial pilot plant fed by drinking water. However, the length of the pilot plant, which was comprised of 6 loops with 31 meters each, allowed for biofilm accumulation upstream of each sampling point to influence the final counts. As a result, a non-linear 
regression model to fit the densities of attached bacteria as a function of pipe surface and distance from the treatment plant was developed.

In the present study, the use of a flow cell (with little or no variation along the axis of sampling) allowed for a meaningful discrimination to be obtained between the influence of nutrients, flow regime and surface material on biofilm formation. Nevertheless, because only two different conditions for each factor were analysed, there is a need to expand the range of conditions tested in order to gather additional information. For instance, it was not determined whether the influence of flow would be so relevant if nutrient concentrations were even higher, or if the relationship between the increase of flow rate and TB in biofilms is linear. Testing different support materials would also probably increase the relevance of this factor, as some studies report materials with much higher differences than those found between PVC and SS (Rogers et al. 1994a; Niquette et al. 2000). Nevertheless, this study provides a framework that future studies can be compared with.

From the most relevant to the least relevant factor, biofilm total bacteria accumulation increases due to the addition of nutrients, the use of turbulent instead of laminar flow rate, and the use of PVC instead of SS as the support material. In the future, further conditions should be tested so that the relationships can be better understood.

\section{Comparison between bacteria on biofilms and planktonic bacteria}

The possibility of using the CFU or TB of planktonic bacteria as a way to infer the level of development of biofilms on the pipe surface has been previously suggested (van der Wende et al. 1989; Kerr et al. 1999; Boe-Hansen et al. 2002). In the study by Kerr et al. (1999) the correlation coefficients reported for CFU, calculated for four different Robbins devices each containing coupons with different materials, were all $>0.80$. However, these values were obtained for systems where the nutrient concentration and flow regime were kept constant. The lower value for the correlation in this study can be explained by the different conditions tested in the system, which are able to alter the relationship of equilibrium that exists between planktonic and attached bacteria. The possibility of using this kind of relationship in real drinking water systems is therefore only reliable for systems with stable conditions.

\section{Conclusions}

The ability to predict biofilm accumulation and biofilm growth potential in water distribution networks, based on the system characteristics and water parameters (both chemical and microbiological), would bring obvious advantages in the monitoring and control of tap water quality. Nevertheless, efforts to develop a general model have been hindered by the lack of understanding of how and to what extent a large number of factors (either alone or in interaction with other factors) affect biofilms. This in vitro study represents, to the authors' knowledge, the first to quantify the influence that three different factors have on TB and CFU biofilm counts. From the most relevant to the least relevant factor, the total and culturable bacteria in biofilms increased due to the addition of nutrients $(\mathrm{F}=20.005 ; p<0.001)$, the use of turbulent $(\operatorname{Re}=11000)$ instead of laminar $(\operatorname{Re}=2000)$ hydrodynamic flows $(F=9.173$; $p<0.001)$ and the use of PVC instead of SS as the support material $(\mathrm{F}=2.848 ; p=0.060)$. In addition, the extent to which interactions between pairs of factors affect biofilm counts has also been determined (namely interactions between surface and flow $[\mathrm{F}=8.235 ; p<0.001]$ and also flow and nutrients $[\mathrm{F}=5.498 ; p<0.05])$. Although the practical use of these conclusions by drinking network companies is still limited, the information provided here might be used as a framework for future studies testing other factors or more conditions to rely upon.

\section{Acknowledgments}

This work was supported by the Fundação para a Ciência e Tecnologia (PhD grant SFRH/BD/4705/ 2001 and Project POCTI/2000/ESP/35849) and by the European Commission Research Project SAFER (Contract No. EVK1-CT-2002-00108).

\section{Disclaimer}

Authors are solely responsible for the work and the work presented does not represent the opinion of the Community and the Community is not responsible for the use that might be made of the data appearing therein.

\section{References}

Block JC, Haudidier K, Paquin JL, Miazga J, Levi Y. 1993. Biofilm accumulation in drinking water distribuition systems. Biofouling 6:333-343.

Boe-Hansen R, Albrechtsen HJ, Arvin E, Jorgensen C. 2002. Bulk water phase and biofilm growth in drinking water at low nutrient conditions. Water Res 36:4477-4486.

Camper A, Burr M, Ellis B, Butterfield P, Abernathy C. 1999. Development and structure of drinking water biofilms and techniques for their study. J Appl Microbiol 85:1S-12S.

Dunsmore BC, Jacobsen A, Hall-Stoodley L, Bass CJ, Lappin-Scott HM, Stoodley P. 2002. The influence of fluid shear on the structure and material properties of sulphatereducing bacterial biofilms. J Ind Microbiol Biotech 29: $347-353$. 
Frias J, Ribas F, Lucena F. 2001. Effects of different nutrients on bacterial growth in a pilot distribution system. Antonie Leeuwenhoek 80:129-138.

Holden B, Greetham M, Croll BT, Scutt J. 1995. The effect of changing inter process and final disinfection reagents on corrosion and biofilm growth in distribution pipes. Water Sci Technol 32:213-220.

Horn H, Reiff H, Morgenroth E. 2003. Simulation of growth and detachment in biofilm systems under defined hydrodynamic conditions. Biotechnol Bioeng 81:607-617.

Keevil CW. 2002. Pathogens in environmental biofilms. In: Bitton G, editor. The encyclopaedia of environmental microbiology. New York: Wiley Interscience. pp 2339-2356.

Kerr CJ, Osborn KS, Robson GD, Handley PS. 1999. The relationship between pipe material and biofilm formation in a laboratory model system. J Appl Microbiol 85:29S - 38S.

Morin P, Camper AK. 1997. Attachment and fate of carbon fines in simulated drinking water distribution system biofilms. Water Res 31:399-410.

Niquette P, Servais P, Savoir R. 2000. Impacts of pipe materials on densities of fixed bacterial biomass in a drinking water distribution system. Water Res 34:1952-1956.

Pallant J. 2001. SPSS survival manual. Philadelphia: Open University Press.

Pedersen K. 1990. Biofilm development on stainless-steel and PVC surfaces in drinking-water. Water Res 24:239-243.

Pereira MO, Morin P, Vieira MJ, Melo LF. 2002a. A versatile reactor for continuous monitoring of biofilm properties in laboratory and industrial conditions. Lett Appl Microbiol 34:22-26.

Pereira MO, Kuehn M, Wuertz S, Neu T, Melo LF. 2002b. Effect of flow regime on the architecture of a Pseudomonas fluorescens biofilm. Biotechnol Bioeng 78:164-171.

Prentice T. 2002. Overview. In: Murray C, Lopez A, editors. The world health report 2002: reducing risks, promoting healthy life. Geneva: World Health Organization. pp 7-14.

Rogers J, Dowsett AB, Dennis PJ, Lee JV, Keevil CW. 1994a. Influence of plumbing materials on biofilm formation and growth of Legionella-pneumophila in potable water-systems. Appl Environ Microb 60:1842-1851.
Rogers J, Dowsett AB, Dennis PJ, Lee JV, Keevil CW. 1994b. Influence of temperature and plumbing material selection on biofilm formation and growth of Legionella-pneumophila in a model potable water-system containing complex microbialflora. Appl Environ Microb 60:1585-1592.

Saby S, Sibille I, Mathieu L, Paquin JL, Block JC. 1997. Influence of water chlorination on the counting of bacteria with DAPI (4',6-diamidino-2-phenylindole). Appl Environ Microbiol 63:1564-1569.

Soini SM, Koskinen KT, Vilenius MJ, Puhakka JA. 2002. Effects of fluid-flow velocity and quality on planktonic and sessile microbial growth in water hydraulic systems. Water Res 36:3812-3820

Stoodley P, Dodds I, Boyle JD, Lappin-Scott HM. 1999. Influence of hydrodynamics and nutrients on biofilm structure. J Appl Microbiol 85:19S-28S.

van der Kooij D. 1992. Assimilable organic-carbon as an indicator of bacterial regrowth. J Am Water Works Ass 84:57-65.

van der Kooij D. 1999. Potential for biofilm development in drinking water distribution systems. J Appl Microbiol 85:39S $44 \mathrm{~S}$.

van der Wende E, Characklis WG, Smith DB. 1989. Biofilms and bacterial drinking water quality. Water Res 23:1313-1322.

Vieira MJ, Melo LF. 1999. Intrinsic kinetics of biofilms formed under turbulent flow and low substrate concentrations. Bioprocess Eng 20:363-368.

Vieira MJ, Pinheiro MM, Melo LF. 1993. Biofilm formationhydrodynamic effects on internal diffusion and structure. Biofouling 7:67-80.

Volk CJ, LeChevallier MW. 1999. Impacts of the reduction of nutrient levels on bacterial water quality in distribution systems. Appl Environ Microbiol 65:4957-4966.

Wasche S, Horn H, Hempel DC. 2002. Influence of growth conditions on biofilm development and mass transfer at the bulk/biofilm interface. Water Res 36:4775-4784.

Zacheus OM, Iivanainen EK, Nissinen TK, Lehtola MJ, Martikainen PJ. 2000. Bacterial biofilm formation on polyvinyl chloride, polyethylene and stainless steel exposed to ozonated water. Water Res 34:63-70. 